\title{
Orman Yangın İşçilerinin İzometrik Kavrama Kuvveti Üzerine Bir Araştırma
}

\author{
*Korhan ENEZ ${ }^{1}$ \\ ${ }^{1}$ Kastamonu Üniversitesi, Orman Fakültesi, Orman İnşaatı-Geodezi ve Fotogrametri Anabilim Dalı, 37150, \\ Kastamomu, Türkiye \\ "Corresponding Autor: korhanenez@kastamonu.edu.tr
}

Geliş Tarihi: 27.10.2016

\begin{abstract}
Özet
Ormanların sürdürülebilir bir yaklaşımla toplum hizmetine sunulmasını olumsuz yönde etkileyen en önemli faktörlerden biri de orman yangınlarıdır. Orman yangınlarıyla mücadele iyi bir organizasyonu gerektirdiği gibi çalışan işçiler içinde yüksek düzeyde kas kuvveti gerektirmektedir. Orman yangınlarındaki iş organizasyonunda çalışanlara ait görev dağılımı yaparken veya orman yangın işçisi seçiminde bulunurken kas gücünün bilinmesine gerek duyulabilir. Bu çalışma ile Kastamonu ve Bursa yöresindeki orman yangın işçilerinin "maksimum izometrik istemli kavrama kuvveti" kapasitesini belirleyerek Türk insanına ait kavrama kuvvetlerindeki yerinin ortaya konulması hedeflenmiştir. Böylece orman yancin işçilerinin maksimum izometrik el kavrama kuvveti yaş, vücut pozisyonu ve desteğe bağlı olarak belirlenmiş, Türk insanına ve diğer bazı milletlere ait kavrama kuvveti ile karşılaştırılmıştır. Beraberinde orman yangın işçilerinin el uzunlukları ile kullandıkları ekipmanlar arasındaki uyum da araştırılmıştır.
\end{abstract}

Anahtar Kelimeler: İzometrik Kavrama Kuvveti, El uzunluğu, Orman Yangın İşçisi

\section{A Study on the Determining the Isometric Hand Grip Strength of Fireworkers}

\begin{abstract}
Forests fires are one of the important factors effecting negatively to public uses of forests and its functions. To combat with forest fires it is required to have a good organization and require a high level of muscle strength for workers. Muscle strength was needed to be known for selection the employees or making the task distribution on forest fires. This study was aimed to find out the location of the grip forces of Turkish people, by determining "maximum isometric hand grip strength" of fire worker, working at Kastamonu and Bursa Regions. Therefore, the maximum isometric of hand grip strength was determined, depending on age, body posture, and its support. The results of grip strength of people in Turkey and other nations were compared.
\end{abstract}

Key Words: Isometric Hand Grip Strength, hand length, Forest fire workers

\section{Giriş}

Dünyada ve ülkemizde ormanların tespit edilmiş ve uluslararası kabul görmüş çok yönlü fonksiyonları vardır. $\mathrm{Bu}$ fonksiyonların sürdürülebilir bir yaklaşımla toplum hizmetine sunulmasını olumsuz yönde etkileyen en önemli faktörlerden biri de orman yangınlarıdir.

Ülkemizde 1988 yılından 2015 yılına kadar 58125 adet orman yangını çıkmıştır. Geçen süre içerisinde 298699 ha ormanlık alan zarar görmüştür(URL-1). Bununla birlikte 1937 2007 yılları arası veriler değerlendirildiğinde y1llık ortalama 1167 adet yangına karşı1ık olarak 1635284 ha orman alanının yandığı ve yangın başına 19,11 ha orman alanının zarar gördüğü tespit edilmiştir (URL-1; Arıcak ve ark., 2014). Çeşitli nedenlere dayandırılan orman yangınlarının nedeni her ne olursa olsun yangınlarla mücadelenin büyük bir kısmı insan gücü ile yapılmaktadır. Orman yangınlarının söndürülmesi ve yangınla mücadele için çeşitli araç ve malzemelerle donatılmış yangın söndürme ekipleri kurulmuştur. Bunlar kendi arasında ilk müdahale ekipleri, arazöz ekipleri ve helikopter ekipleri olmak üzere üç kısma ayrılmaktadır. İlk müdahale ekibinde çalışan yangın işçileri orman yangınına tırmık, tahra, çapa kazma, balta, su tulumu, motorlu testere gibi mücadele ekipmanları ve koruyucu malzemelerle müdahale ederler. Bu çalışmalar kas gücü ile yapıldı̆̆ 1 için statik (izometrik) kas gücü bir süre sonra tükenmekte, dinçliğini kaybetmekte ve çalışma performansı 
düşmektedir (URL-2). İnsanın önemli fiziksel kapasitelerinden birisi olan kas kuvveti yangin işçileri için hayati anlam ifade etmektedir. İş taleplerinin insan kapasitesine uygun olmasina çalışarak yorgunluğu ve yorgunluğun neden olabileceği işe bağlı kas iskelet hastalıklarını azaltmayı, verimliliği - kaliteyi artırmayı, maliyetleri azaltmayı amaçlayan ergonomi bilimince topluluğun kuvvet kapasitesinin hesaplanmas1 gerekir. Böylece topluluğun büyük bir kısmının kuvvet gerektiren bir işin gerektirdiği yorgunluğa neden olmayacak kuvvet oranı hesaplanabilir (Ekşioğlu ve ark., 2008).

İnsan kas kuvveti efor türüne bağlı olarak statik (izometrik) veya dinamik olabilir. Statik kuvvet uygulamada kasın bağlı olduğu segment hareketi minimaldir. Dinamik kas kuvveti ise izotonik (sabit gerilimli) veya izokinetik (sabit hızlı) olabilir. Uygulamaya bağlı olarak statik kas kuvveti tekrarlı veya sürekli; dinamik kuvvetler ise izoinertial (isoinertial) kas kuvveti, psikofiziksel kas kuvveti, veya tekrarlı dinamik kuvvetler şeklinde olabilir (Ekşioğlu ve ark., 2008). İzometrik kas kuvveti kasın ilgili olduğu eklemlerin sabit kalarak, bir kasın istemli olarak yalnızca bir maksimum kasılmayla ürettiği kuvvet veya torktur. İzometrik kuvvetler arasinda el kavram kuvveti, parmakkavrama kuvveti, kol kaldırma kuvveti, omuz kaldırma kuvveti, bacak kaldırma kuvveti, bel kaldırma kuvveti, el itme kuvveti ve el çekme kuvveti siralanabilir (Ekşioğlu ve ark., 2008; Mital ve Kumar,1998).

El kavrama kuvvet verileri, özellikle el yoğunluklu işler ve el aleti tasarımı için önemlidir. El kavrama kuvvetini etkileyen ana faktörler cinsiyet, yaş, vücut ve eklem pozisyonları, kalıtım, kondisyon durumu, sağ veya sol el, uygulama hızı, uygulama süresi ve tekrar sayısı, kavrama çapı ve aralığı şeklinde sıralanabilir (Ekşoğlu, 2004; Ekşioğlu ve ark., 2008).
$\mathrm{Bu}$ çalışmanın amacı, Kastamonu ve Bursa yöresindeki orman yangın işçilerinin "maksimum izometrik istemli kavrama kuvveti" kapasitelerinin belirlenerek, Türk insanına ait kavrama kuvveti dağılımı ile kıyaslanmasıdır.

\section{Materyal ve Yöntem \\ Katılımcılar}

$\mathrm{Bu}$ çalışma Kastamonu ve Bursa yöresinde Orman Bölge Müdürlüklerinde yangın sezonunda "orman yangın işçisi" statüsünde çalışanları kapsamaktadır. Çalışanlarda maksimal kuvvetlerini etkileyecek hastalık ve rahatsızlıkların olmamasına özen gösterilmiş ve bu durumun tespit edilmesi için uygulanan ankette sağlık soruları eklemek sureti ile kontrol edilmiştir. Ancak çalışmada örneklem büyüklügü tespit edilemeyip gönüllülük esasına göre katılımcılar tespit edilmiştir. Çalışmaya katılan işçilerin İşletme Müdürlükleri ve İşletme Şefliklerine göre dağılımı Tablo 1'de verilmiştir.

\section{Ekipman}

El kavrama kuvvetinin ölçülmesi için Saehan marka SH5001 model hidrolik el dinamometresi kullanılmıştır (Şekil 1). Bu dinamometre 0 kg-f (kg-kuvvet) den 90 kg-f'e kadar olan kuvvet değerlerini ölçebilmektedir. Birbirine paralel iki sap1 olan dinamometre, 5 ayrı genişlikte $(1,3 \mathrm{~cm}$ artışlarla 3,5 cm'den 8,5 cm'ye kadar) sapan (kavrama aralığı) ayarı ile değişik el ölçüsüne sahip kişilere göre kurulabilir. Katılımcıların el uzunluğu (bilekten orta parmağın hizasına kadar) dijital kumpas ile, boy uzunlukları çelik şerit metre ile, ağırlıkları elektronik baskül ile ölçülmüștür. Kullanılan baskül maksimum 150 kg tartma kapasitesine sahip ve ayn zamanda $100 \mathrm{~g}$ hassasiyette ölçüm yapabilmektedir. 
Tablo 1. Çalışmaya katılan orman yangın işçilerinin işletme şefliklere göre dağılımı

\begin{tabular}{|c|c|c|c|}
\hline $\begin{array}{l}\text { Orman Bölge } \\
\text { Müdürlüğü }\end{array}$ & $\begin{array}{l}\text { Orman İşletme } \\
\text { Müdürlüğü }\end{array}$ & $\begin{array}{l}\text { Orman İşletme } \\
\text { Sefliŏi } i\end{array}$ & $\begin{array}{l}\text { Yangin İşçisi } \\
\text { Sayıs1 }\end{array}$ \\
\hline \multirow{9}{*}{ 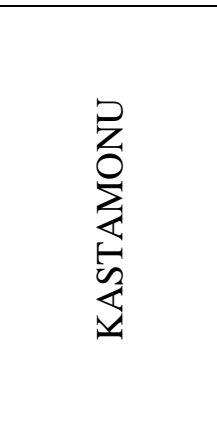 } & Kastamonu & Değirmenciler & 22 \\
\hline & Karadere & Handüzü & 9 \\
\hline & & Çaltepe & 5 \\
\hline & & Karadere & 5 \\
\hline & Taşköprü & Taşköprü & 25 \\
\hline & & Hanönü & 7 \\
\hline & Tosya & Tosya & 14 \\
\hline & Araç & Araç & 7 \\
\hline & Daday & Daday & 8 \\
\hline TOPLAM & & & 102 \\
\hline \multirow{12}{*}{ 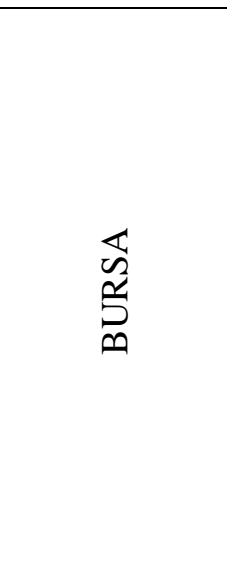 } & Bursa & Merkez & 12 \\
\hline & & Kestel & 4 \\
\hline & & Çalı & 5 \\
\hline & İnegöl & İnegöl & 8 \\
\hline & & Yenişehir & 3 \\
\hline & & Mahmudiye & 3 \\
\hline & Orhaneli & Orhaneli & 11 \\
\hline & & Keles & 3 \\
\hline & & Kumla & 1 \\
\hline & & Orhangazi & 1 \\
\hline & & Mudanya & 3 \\
\hline & & İznik & 2 \\
\hline \multicolumn{2}{|c|}{ TOPLAM } & & 56 \\
\hline \multicolumn{2}{|c|}{ GENEL TOPLAM } & & 158 \\
\hline
\end{tabular}

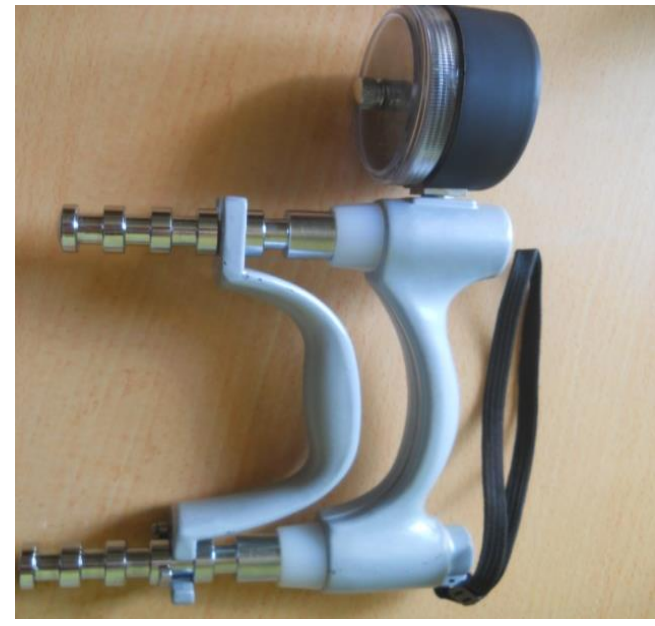

Şekil 1. Saehan marka SH5001 model hidrolik

\section{Deney Prosedürü}

Deneysel görev, maksimum istemli izometrik el kavrama kontraksiyonlarının (MIK: maksimum istemli kontraksiyonun (kasilma);

isometric power grip strength) vücut pozisyonu, dinamometre ağırlığı ve el kombinasyonlarının bir fonksiyonu olarak yapılmasını sağlamaktır (toplam 8 kombinasyon). Çalışmanın amacının işçiye açıklamasından sonra, katılmak isteyen her bir işçiye orman yangın iş̧̧ilerinin el kavrama kuvveti ölçüm anketi doldurtularak kalp hastalığı, diyabet, ülser, romatizma, hipertansiyon ve kas-iskelet hastalıkları olup olmadıklarından emin olunmuştur. Katılımcılar testlerin amacı, prosedürler ve kurallar 
hakkında detaylı bilgileri içeren bir 'Kabul' formunu okuyup imzalamışlardır. Katılımcılar kendi kişisel bilgilerini (yaş, medeni hal, eğitim durumu, işle ilgili sağlik kontrolü geçirip geçirmediği, sağlı nedeni ile işi aksatma durumu, çalışma zamanları dışında başkaca bir işle iştigal edip etmediği, iş tecrübesi, işe yönelik bir eğitim alıp almadığı, yaptığı işle ilgi görev dağılımları, baskın elleri, işin güçlük durumu ve dinlenme mollalarının uzunlukları) içeren 'Kişisel Bilgi' formunu doldurmuşlardır. Sonrasında işçilerin boy, ağırlık ve el boyutları ölçülerek kaydedilmiştir (Ekşioğlu ve ark., 2008).

$\mathrm{Bu}$ aşamalardan sonra, katılımcılar MIK ölçmede kullanılan dinamometre ve uygulanacak prosedürlere alıştırılmıştır. Gerçek testlerden önce, katılımcıların dinamometrenin kendilerine en rahat gelen ve maksimal kuvveti uygulayabileceklerine inandıkları kavrama aralığını (tercih-edilen span: prefered span) deneyerek bulmaları sağlanmıştır. $\quad 158$ katılımcının 120'si dinamometrenin 2. ayarın $1(4,8 \mathrm{~cm}), 38^{\prime} \mathrm{i}$ ise 3 . ayarı $(6,1 \mathrm{~cm})$ tercih etmiştir.

Sonrasında dinamometre spanı katılımcinın tercih etmiş olduğu spana ayarlanmış ve katılımcının maksimal el kavrama kuvveti Caldwell (1974) protokolüne göre ölçülerek kaydedilmiştir (Ekşioğlu ve ark., 2008). Bu protokole göre, katılımc1 ayakta ve oturarak dinamometreyi sarsmadan yaklaşık bir (1) saniyede maksimum kavrama kuvvetine yükseltmiş ve bu kuvveti dört (4) saniye kadar tutmuştur. Bu test, her dört pozisyonun her biri ve her iki el için en az iki kere tekrarlanmıştır (her işçi için asgari 16 test).Tekrarlara, kuvvet değerleri arasındaki fark \%12 den az olana kadar devam edilmiş ve her bir kuvvet testinden sonra 1 dakika 30 saniye dinlenme molası verilerek lokal kas yorgunluğu en aza indirilmeye çalışılmıştır.

İşçilere deneye gelmeden en az iki (2) saat önceden yemek yemeyi kesmeleri ancak aç olarak gelmemeleri, sigara ve kafeinli içeceklerden uzak durmaları ve uykusuz olarak deneylere gelmemeleri hakkında önceden talimat verilmiştir (Ekşioğlu ve ark, 2008).
El kavrama kuvveti testleri dört ayrı pozisyonda yapılmış ve her iki el için ölçülen veriler (1) ayakta, (2) ayakta ve dinamometre destekli, (3) nötral pozisyonda oturarak ve (4) nötral pozisyonda oturarak ve dinamometre destekli olarak kayıt altına alınmıştır. Bu pozisyonların her biri her iki el için en az iki kez tekrarlanmıştır (her bir işçi için 16 test). Ayakta destekli veya desteksiz yapılan ölçümlerde katılımcının ayaklarının omuz genişliğinde açmaları sağlanmıştır. Oturarak yapılan ölçümlerde ise katılımcı nötral bir vücut pozisyonundadır. Buna göre katılımcılar (işçiler) sırt ve ayakları iyice destekli ve rahat bir dik oturuş pozisyonunda olmuşlardır. Kalça ve diz açıları $90^{\circ}$ ve bilek düz olacak şekilde duruşlardır. Destekli durumlarda dinamometrenin ağırlığ deney yöneticisi tarafından desteklenmiştir.

\section{Deney Tasarımı}

Deneysel bağımsız değişkenler şunlardır: vücut pozisyonu (iki seviyede: ayakta ve otururken), dinamometre durumu (destekli veya desteksiz), el (baskın ve baskın olmayan), yaş grupları (18-29, 30-39, 40-49 ve 50<). Bağımlı (yanıt) değişken ise "izometrik maksimum istemli el kavrama kuvveti" dir. Her kat1lımc1 on altı deney oturumunu rastsal olarak yerine getirmiştir. Bağımlı değişkenlerin bir tane olduğu durumlarda bağımsız t testi, birden fazla bağımsız değişkenler olduğu durumlarda tek yönlü varyans analizi, daha önce yapılmış çalışmalarla kıyaslanırken tek örnek t test istatistikleri uygulanmıştır (Özdamar, 2003; Büyüköztürk, 2010).

\section{Bulgular ve Tartışma}

Kastamonu ve Bursa yöresindeki orman yangın işçilerinin tamamı erkektir. $\mathrm{Bu}$ çalışmaya 102'si Kastamonu'dan ve 56's1 Bursa'dan olmak üzere toplam 158 orman yangın işçisi katılmıştır. Bütün orman yangın işçilerinin yaş aralığı (ortalama \pm standart sapma) $19-64 \quad(39,2 \pm 9,7)$ y1l, boy aralığ 1 (ortalama \pm standart sapma) 156-192 $(172,63 \pm 6,87) \mathrm{cm}$, baskın el uzunluğu 15,3-22 $(18,36 \pm 1,6) \mathrm{cm}$ ve ağırlık (ortalama \pm standart sapma) $49,30-129 \quad(80,97 \pm 14,39) \quad \mathrm{kg}$ olarak 
ölçülmüştür. Bununla birlikte Kastamonu ve Bursa çalışma alanları için ayrı ayrı yaş, boy, el uzunluğu ve kilo bilgileri tablo halinde verilmiştir (Tablo 2).

Tablo 2. Çalışma yörelerine göre orman yangın işçilerinin yaş, boy ve kilo dağılımları

\begin{tabular}{lcccccc}
\hline & \multicolumn{3}{c}{ Kastamonu } & \multicolumn{3}{c}{ Bursa } \\
\hline Yaş & Min. & Max. & Ort. \pm Std.Sapma & Min. & Max. & Ort. \pm Std.Sapma \\
\hline Boy & 19 & 64 & $39,1 \pm 10,3$ & 20 & 56 & $39,34 \pm 8,61$ \\
\hline Kilo & 156 & 192 & $172,03 \pm 6,70$ & 158 & 190 & $173,71 \pm 6,60$ \\
\hline El uzunluğu sağ & 49,3 & 129 & $79,87 \pm 15,06$ & 59 & 120 & $82,99 \pm 12,98$ \\
\hline El uzunluğu sol & 16,8 & 22,0 & $19,2 \pm 1,05$ & 15,30 & 22,0 & $16,8 \pm 1,3$ \\
\hline
\end{tabular}

Orman yangın işçilerinin sosyo-demografik özelliklerinin dağılımına bakıldığında her iki yöredeki çalışanların \%84 oranından daha fazlasının evli olduğu, \%40 civarından en fazla ilkokul mezunu oldukları, bununla birlikte Kastamonu yöresinde yüksekokul mezunu $(\% 7,8)$ olmasına rağmen Bursa yöresindeki çalışanlar arasında yüksekokul mezunu bulunmamaktadır. Kastamonu yöresindeki orman yangın işçilerinin \%91,2'si işle ilgili sağlık kontrolünden geçtiğini belirtirken, Bursa yöresindeki çalışanların \%58,9'u sağlık kontrolünden geçtiklerini belirtmişlerdir. Her iki yörede de \%80'nin üzerindeki orman yangın işçisi sağlık nedeni ile işi aksatmadığını ifade etse de, Kastamonu'da \%18,6's1, Bursa'da \%16,1'i bir ile otuz gün arasinda işlerini aksatmak durumunda kaldıklarını ifade etmişlerdir. Her iki yöredeki yangın işlerinin \%60'ından fazlası başka işte çalışmadığını ifade etmekle birlikte Kastamonu'da \%29,9'u Bursa'da \%14,3'ü çiftçilikle uğraşmaktadır. Çalışanların en \%41,2'si Kastamonu yöresinde yeni başlayan işçiler çoğunlukta iken Bursa yöresinde 20 yıldan daha fazla çalışanlar
\%44,6 ile ilk sırayı oluşturmaktadır. Her iki yöredeki çalışanların \%89'undan fazlası iş ile ilgili mesleki eğitim aldıklarını ifade etmişlerdir. Yangın işindeki göreviniz sorusuna verdikleri cevapların dağılımı işle ilgili aldıkları eğitimin olduğunun göstergesi olarak kabul edilebilir. Görev dağglımlarının oranlarının birbirine yakın olması çalışanların belli bir plan ve eğitim dahilinde işlerini yaptıklarını ifade etmektedir. Her iki grupta da sağ el \%90 üzerinde baskın el konumundadır. Kastamonu yöresindeki çalışanların \%79'u işlerinin "pek güç" olmadığını ifade ederken Bursa yöresindeki yangın işçilerinin de \%48,2'si işlerinin "normal" olduğunu ifade etmişlerdir. Dinlenme molalarında da her iki yöre çalışanları benzer sürelerde mola vermekte olduğu görülmüştür. Bursa yöresindeki çalışanlar \%57,1 ile 10-15 dakikalık mola verdiklerini ifade ederken Kastamonu yöresindeki çalışanların \%20,6's1 10-15 dakika, \%21,6's1 da 15-30 dakikalık molalar verdiklerini ifade etmişlerdir. Yalnız her iki bölgede de 30 dakikanın üzerinde mola vermediklerini ifade etmişlerdir (Tablo 3).

Tablo 3. Orman yangın işçilerinin sosyo-demografik özellikleri

\begin{tabular}{llcccc}
\hline & & \multicolumn{2}{c}{ Kastamonu } & \multicolumn{2}{c}{ Bursa } \\
\hline & & Adet & $\%^{*}$ & Adet & $\%^{*}$ \\
\hline \multirow{3}{*}{ Yaş Grupları } & $18-29$ & 23 & 22,5 & 7 & 12,5 \\
& $30-39$ & 22 & 21,6 & 20 & 35,7 \\
& 4049 & 43 & 42,2 & 23 & 41,1 \\
\multirow{3}{*}{ Medeni Hal } & $50 \leq$ & 14 & 13,7 & 6 & 10,7 \\
& Evli & 86 & 84,3 & 54 & 96,4 \\
& Bekar & 15 & 14,7 & 1 & 1,8 \\
& Dul & 1 & 1 & 1 & 1,8 \\
\hline
\end{tabular}


Tablo 3. Devam1

\begin{tabular}{|c|c|c|c|c|c|}
\hline \multirow{5}{*}{ Eğitim Durumu } & Okur-yazar değil & 4 & 3,9 & 1 & 1,8 \\
\hline & İlkokul & 43 & 42,2 & 25 & 44,7 \\
\hline & Ortaokul ve dengi okul & 18 & 17,6 & 16 & 28,6 \\
\hline & Lise ve dengi okul & 29 & 28,4 & 14 & 25,0 \\
\hline & Yüksekokul & 8 & 7,8 & 0 & 0,0 \\
\hline \multirow{2}{*}{$\begin{array}{l}\text { İş ile ilgili sağlık kontrolünden } \\
\text { geçme }\end{array}$} & Evet & 93 & 91,2 & 33 & 58,9 \\
\hline & Hayır & 9 & 8,8 & 23 & 41,1 \\
\hline \multirow{2}{*}{ Sağlık nedeni ile iş aksatma } & 0-30 gün & 18 & 18,6 & 9 & 16,1 \\
\hline & Aksatmayan & 83 & 81,4 & 47 & 83,9 \\
\hline \multirow{5}{*}{ Çalışma zamanı dışında yaptığı iş } & Çiftçilik & 30 & 29,9 & 8 & 14,29 \\
\hline & İșçi & 1 & 1,0 & 3 & 5,36 \\
\hline & Sanayi işçisi & 2 & 2,0 & 4 & 7,14 \\
\hline & Ticaret & 3 & 3,2 & 3 & 5,36 \\
\hline & Çalışmayan & 65 & 63,9 & 38 & 67,85 \\
\hline \multirow{5}{*}{ Çalışma yılları grup } & $1-5$ y1l & 42 & 41,2 & 9 & 16,1 \\
\hline & $6-10$ y1l & 14 & 13,7 & 11 & 19,6 \\
\hline & $11-15$ y1l & 12 & 11,8 & 4 & 7,1 \\
\hline & $16-20$ y1l & 16 & 15,7 & 7 & 12,5 \\
\hline & $20<$ ve üzeri & 18 & 17,6 & 25 & 44,6 \\
\hline \multirow{2}{*}{$\begin{array}{l}\text { İş ile ilgili mesleki eğitim alma } \\
\text { durumu }\end{array}$} & Evet & 94 & 92,2 & 50 & 89,3 \\
\hline & Hayır & 8 & 7,8 & 6 & 10,7 \\
\hline \multirow{6}{*}{ Yangın işindeki görevi } & Tabancacı & 42 & 41,1 & 4 & 7,1 \\
\hline & Hortumcu & 27 & 26,5 & 5 & 8,9 \\
\hline & Șoför & 4 & 3,9 & 6 & 10,7 \\
\hline & Arazöz șoförü & 17 & 16,7 & 15 & 26,8 \\
\hline & Arazöz operatörü & 2 & 2 & 4 & 7,1 \\
\hline & Yangın söndürme & 10 & 9,8 & 22 & 39,3 \\
\hline \multirow{2}{*}{ Baskın el } & Să̆ & 92 & 90,2 & 54 & 96,4 \\
\hline & Sol & 10 & 9,8 & 2 & 3,6 \\
\hline \multirow{5}{*}{ İşin güçlük durumu } & Gayet güc & 2 & 2 & 6 & 10,7 \\
\hline & Güç & 2 & 2 & 20 & 35,7 \\
\hline & Normal & 16 & 15,7 & 27 & 48,2 \\
\hline & Pek güç değil & 81 & 79,4 & 3 & 5,4 \\
\hline & Hiç güç değil & 1 & 1 & 0 & 0,0 \\
\hline \multirow{4}{*}{ Dinlenme molası uzunlukları } & 5 dakika & 0 & 0 & 1 & 1,8 \\
\hline & 5-10 dakika & 59 & 57,8 & 12 & 21,4 \\
\hline & 10-15 dakika & 21 & 20,6 & 32 & 57,1 \\
\hline & 15-30 dakika & 22 & 21,6 & 11 & 19,6 \\
\hline
\end{tabular}

Orman yangın işçilerinin sağlık durumlarına bakıldığında maksimum istemli izometrik el kavrama kuvvetini doğrudan etkileyecek hastalıklara ve şikayetlere rastlanmamıştır. Bununla birlikte orman yangın işçilerinin çalışma esnasında ve aralıklarla söz konusu olan rahatsızlıklarına bakıldığında Kastamonu yöresindekilerin \%70,6'sının Bursa yöresindekilerin ise \%71, 4’ünün hiçbir sağlı probleminden yakınmadığı görülmüştür. Beraberinde her iki yöre çalışanı da bel ağrısından yakındıklarını ifade etmişlerdir (Tablo 4). Çalışanlardan en son doktordan öğrendikleri hastalıkları sıralarlarken Kastamonu yöresinde çalışanlar en fazla mide rahatsızlığ1 (ülser) $(\% 4,9)$ ifade ederken, Bursa yöresinde çalışanlar göz ameliyatı $(\% 7,2)$ olduklarını ifade etmişlerdir (Tablo 4). 
Tablo 4. Orman yangın işlerinin sağlık durumlarının dağılımı

\begin{tabular}{|c|c|c|c|c|c|}
\hline & & Kastamonu & & Bursa & \\
\hline & & Adet & $\%^{*}$ & Adet & $\%^{*}$ \\
\hline \multirow{13}{*}{$\begin{array}{l}\text { Sağlik problemlerinden } \\
\text { yakınma }\end{array}$} & Bel ağrısı(iş sırasında) & 4 & 3,9 & 9 & 16,1 \\
\hline & Bel ağrısı(ara sıra) & 10 & 9,8 & - & - \\
\hline & Kulakta duyma zorluğu & 3 & 2,9 & - & - \\
\hline & Gözde görme zorluğu & 1 & 1,0 & - & - \\
\hline & Romatizma & 3 & 2,9 & 1 & 1,8 \\
\hline & Sert omuz ve kürek kemiği & 2 & 2,0 & 3 & 5,4 \\
\hline & Varis ( ara sira) & 2 & 2,0 & - & - \\
\hline & Omuz ve boyun ağrısı & 1 & 1,0 & - & - \\
\hline & Kol ve bacak ağrısı & 1 & 1,0 & - & - \\
\hline & Parmaklarda & 1 & 1,0 & - & - \\
\hline & Sinirsel baş ağrısı & 1 & 1,0 & 3 & 5,4 \\
\hline & Bronşit ve nezle & 1 & 1,0 & - & - \\
\hline & Hiçbir rahatsızlı̆̆ım yok & 72 & 70,6 & 40 & 71,4 \\
\hline \multirow{18}{*}{$\begin{array}{l}\text { Doktordan öğrenilen } \\
\text { en son hastalık }\end{array}$} & Mide rahatsızlığı(ülser) & 5 & 4,9 & - & - \\
\hline & Mide ameliyatı & 1 & 1,0 & - & - \\
\hline & Fitık(kasık) & 1 & 1,0 & 1 & 1,8 \\
\hline & Tansiyon & 5 & 4,9 & - & - \\
\hline & Reflü ve prostat & 1 & 1,0 & 2 & 3,6 \\
\hline & Göz ameliyatı & 1 & 1,0 & 4 & 7,2 \\
\hline & Tansiyon ve bel fitığı & 1 & 1,0 & 2 & 3,6 \\
\hline & Reflü & 1 & 1,0 & - & - \\
\hline & Kalp (anjiyo) & 2 & 2,0 & - & - \\
\hline & Tansiyon ve şeker & 1 & 1,0 & 1 & 1,8 \\
\hline & Böbrekte kum & 2 & 2,0 & - & - \\
\hline & Bel fitığ & 4 & 3,9 & - & - \\
\hline & Bilek kırılmış(daha önce) & 1 & 1,0 & - & - \\
\hline & Sinüzit & 1 & 1,0 & - & - \\
\hline & Bacak kırılmış(daha önceden) & 1 & 1,0 & 2 & 3,6 \\
\hline & Kronik bronşit & 1 & 1,0 & 1 & 1 \\
\hline & Gastrit & 1 & 1,0 & - & - \\
\hline & Hayır (yok) & 72 & 70,6 & 43 & 76,7 \\
\hline
\end{tabular}

*Yüzdeler Kastamonu yöresi için 102, Bursa yöresi için 56 orman yangın iş̧̧isine göre hesaplanmıştır.

Orman yangın işçilerinin çay, sigara ve alkol gibi maddelerin kullanım durumları, s1klıklarına ait veriler s1k sik, günlük, ara sira ve kullanmıyorum şeklinde gruplandırılmış olup çayı hemen hemen hepsinin tükettiği sadece Kastamonu'da $\% 2$ oranında tüketmediğini ifade edenlerin olduğu görülmüştür (Tablo 5).
Yaş gruplarına göre sekiz test pozisyonundaki ortalama, standart sapma ve aralık izometrik maksimum kavrama kuvveti değerleri kg-f (kg-kuvvet) cinsinden Kastamonu yöresi için Tablo 6 (Enez ve ark., 2013) Bursa yöresi için Tablo 7 ve her ikisi birlikte de Tablo 8'de gösterilmiştir. Kastamonu yöresi için yaş grupları arasındaki izometrik kas kuvvetinin fark1 varyans analizi 
ile ortaya konulmuştur. Buna göre oturarak desteksiz baskın olmayan el kavrama kuvvetlerinde yaş grupları arasında istatistiksel olarak anlamlı bir fark vardır $(\mathrm{p}<0,05)$. Diğer yaş gruplarında hiçbir ölçüm pozisyonunda yaş grupları arasında fark görülmemiştir. Oluşan farkın hangi gruplar arasında olduğunu ya da hangi grup ya da gruplardan kaynaklandığını bulmak için Tukey testi uygulanmıştır. Buna göre 30-39 yaş grubu ile 50 yaşından büyüklerin oluşturduğu yaş grupları arasında farkın önemli olduğu bulunmuştur $(\mathrm{p}<0,05)$ (Enez ve ark., 2013).

Tablo 5. Orman yangın işçilerinin madde kullanma alışkanlıklarının dağılımı

\begin{tabular}{lccccccccccccc}
\hline & \multicolumn{4}{c}{ Sigara } & \multicolumn{4}{c}{ Alkol } & \multicolumn{4}{c}{ Çay } \\
\hline & \multicolumn{1}{c}{ Kastamonu } & \multicolumn{2}{c}{ Bursa } & \multicolumn{1}{c}{ Kastamonu } & \multicolumn{1}{c}{ Bursa } & \multicolumn{3}{c}{ Kastamonu } & \multicolumn{2}{c}{ Bursa } \\
\hline & Adet & $\%^{*}$ & Adet & $\%^{*}$ & Adet & $\%^{*}$ & Adet & $\%^{*}$ & Adet & $\%^{*}$ & Adet & $\%^{*}$ \\
\hline S1k s1k & 36 & 35,3 & 5 & 9,0 & 2 & 2,0 & - & - & 52 & 51,0 & 12 & 21,4 \\
Günlük & 15 & 14,7 & 29 & 51,7 & 2 & 2,0 & - & - & 38 & 37,3 & 38 & 67,9 \\
Ara sira & 9 & 8,8 & 3 & 5,3 & 16 & 15,7 & 13 & 23,2 & 10 & 9,8 & 6 & 10,7 \\
Kullanmiyorum & 42 & 41,2 & 19 & 34,0 & 82 & 80,4 & 43 & 76,8 & 2 & 2,0 & - & - \\
\hline
\end{tabular}

Tablo 6. Kastamonu yöresi yangın işçilerinin yaşa göre sekiz test pozisyonundaki kavrama kuvveti değerleri (kg-f)

$*_{n}=$ Örneklem sayısl; BA: Ayakta desteksiz baskın el kavrama kuvveti; BOA: Ayakta desteksiz baskin olmayan el kavrama

\begin{tabular}{|c|c|c|c|c|c|c|c|c|c|}
\hline $\begin{array}{l}\text { Yaş } \\
\text { Aralığ }\end{array}$ & $\mathrm{n}^{*}$ & $\mathrm{BA}^{*}$ & $\mathrm{BOA}^{*}$ & BAD* & BOAD* & BO* & BOO* & BOD* & BOOD* \\
\hline $18-29$ & 23 & $\begin{array}{l}50,00 \pm 8,10 \\
(32,50-66,00)\end{array}$ & $\begin{array}{l}49,32 \pm 8.64 \\
(32,75-64,50)\end{array}$ & $\begin{array}{l}52,02 \pm 8.74 \\
(35,00-71,25)\end{array}$ & \begin{tabular}{|l}
$51,22 \pm 8.73$ \\
$(33,50-69,00)$
\end{tabular} & $\begin{array}{l}50,30 \pm 7.97 \\
(34,75-67,50)\end{array}$ & $\begin{array}{l}50,62 \pm 8.18 \\
(31,50-65,00)\end{array}$ & $\begin{array}{l}51,99 \pm 7.85 \\
(36,00-65,75)\end{array}$ & $\begin{array}{l}51,92 \pm 8.41 \\
(34,25-68,25)\end{array}$ \\
\hline $30-39$ & 22 & $\begin{array}{l}48,90 \pm 6,17 \\
(38,50-62,00)\end{array}$ & $\begin{array}{l}50,30 \pm 5,69 \\
(38,00-64,50)\end{array}$ & $\begin{array}{l}51,11 \pm 5,98 \\
(43,50-64,50)\end{array}$ & $\begin{array}{l}52,47 \pm 5,40 \\
(44,00-65,00)\end{array}$ & $\begin{array}{l}50,34 \pm 6,34 \\
(39,00-65,00)\end{array}$ & $\begin{array}{l}50,92 \pm 5,13 \\
(41,25-62,00)\end{array}$ & $\begin{array}{l}51,74 \pm 5,99 \\
(43,00-63,75)\end{array}$ & $\begin{array}{l}51,69 \pm 5,46 \\
(42,75-62,50)\end{array}$ \\
\hline $40-49$ & 43 & $\begin{array}{l}47,24 \pm 8,75 \\
(33,00-71,00)\end{array}$ & $\begin{array}{l}48,08 \pm 8,92 \\
(30,25-71,25)\end{array}$ & $\begin{array}{l}49,30 \pm 8,67 \\
(33,50-76,00)\end{array}$ & $\begin{array}{l}49,97 \pm 8,78 \\
(33,25-74,75)\end{array}$ & $\begin{array}{l}48,67 \pm 8,20 \\
(30,75-72,50)\end{array}$ & $\begin{array}{l}48,50 \pm 8,59 \\
(31,50-71,00)\end{array}$ & $\begin{array}{l}50,06 \pm 9,04 \\
(33,50-77,00)\end{array}$ & $\begin{array}{l}49,75 \pm 9,03 \\
(33,25-73,00)\end{array}$ \\
\hline $50 \leq$ & 14 & \begin{tabular}{|l|}
$44,59 \pm 8,31$ \\
$(24,00-57,00)$
\end{tabular} & \begin{tabular}{|l|}
$43,66 \pm 9,01$ \\
$(21,75-58,00)$
\end{tabular} & $\begin{array}{l}46,55 \pm 8,80 \\
(23,25-58,00)\end{array}$ & \begin{tabular}{|l|}
$45,07 \pm 9,72$ \\
$(21,25-59,50)$
\end{tabular} & $\begin{array}{l}46,59 \pm 8,90 \\
(23,00-56,50)\end{array}$ & $\begin{array}{l}43,84 \pm 8,80 \\
(21,25-58,00)\end{array}$ & $\begin{array}{l}47,34 \pm 9,01 \\
(23,75-56,50)\end{array}$ & $\begin{array}{l}45,27 \pm 8,85 \\
(22,25-57,25)\end{array}$ \\
\hline Tümü & 102 & $\begin{array}{l}47,86 \pm 8,11 \\
(24,00-71,00)\end{array}$ & $\begin{array}{l}48,23 \pm 8,4 \\
(21,75-71,25)\end{array}$ & $\begin{array}{l}49,93 \pm 8,27 \\
(23,25-76,00)\end{array}$ & $\begin{array}{l}50,12 \pm 8,48 \\
(21,25-74,75)\end{array}$ & $\begin{array}{l}49,12 \pm 7,87 \\
(23,00-72,50)\end{array}$ & $\begin{array}{l}48,86 \pm 8,12 \\
(21,25-71,00)\end{array}$ & $\begin{array}{l}50,49 \pm 8,22 \\
(23,75-77,00)\end{array}$ & $\begin{array}{l}50,04 \pm 8,38 \\
(22,25-73,00)\end{array}$ \\
\hline
\end{tabular}

kuvveti; BAD: Ayakta destekli baskın el kavrama kuvveti; BOAD: Ayakta destekli baskın olmayan el kavrama kuvveti; BO: Otururken desteksiz baskın el kavrama kuvveti; BOO: Otururken desteksiz baskın olmayan el kavrama kuvveti; BOD: Otururken destekli baskın el kavrama kuvveti; BOOD: Otururken destekli baskın olmayan el kavrama kuvveti

Tablo 7. Bursa yöresi yangın işçilerinin yaşa göre sekiz test pozisyonundaki kavrama kuvveti değerleri (kg-f)

\begin{tabular}{|c|c|c|c|c|c|c|c|c|c|}
\hline $\begin{array}{l}\text { Yaş } \\
\text { Aralığ1 }\end{array}$ & $\mathrm{n}^{*}$ & $\mathrm{BA}^{*}$ & $\mathrm{BOA}^{*}$ & BAD* & BOAD* & BO* & BOO* & BOD* & BOOD* \\
\hline $18-29$ & 7 & $\begin{array}{l}45,75 \pm 5,19 \\
(35,50-51,75)\end{array}$ & $\begin{array}{l}43,04 \pm 7,22 \\
(33,00-49,75)\end{array}$ & $\begin{array}{l}46,32 \pm 4,67 \\
(37,75-51,50)\end{array}$ & $\begin{array}{l}42,93 \pm 6,33 \\
(34,50-49,00)\end{array}$ & $\begin{array}{l}46,54 \pm 7,93 \\
(33,75-54,75)\end{array}$ & $\begin{array}{l}47,43 \pm 7,87 \\
(34,00-56,50)\end{array}$ & $\begin{array}{l}46,57 \pm 6,89 \\
36,50-57,00)\end{array}$ & $\begin{array}{l}45,79 \pm 6,48 \\
(34,00-54,50)\end{array}$ \\
\hline $30-39$ & 20 & $\begin{array}{l}48,01 \pm 9,36 \\
(24,50-60,75)\end{array}$ & $\begin{array}{l}45,33 \pm 9,82 \\
(23,50-58,75)\end{array}$ & $\begin{array}{l}47,76 \pm 8,82 \\
(27,50-61,50)\end{array}$ & $\begin{array}{l}44,06 \pm 8,96 \\
(23,00-57,75)\end{array}$ & $\begin{array}{l}48,65 \pm 8,94 \\
(29,00-63,00)\end{array}$ & $\begin{array}{l}46,35 \pm 8,43 \\
(23,50-58,75)\end{array}$ & $\begin{array}{l}47,10 \pm 8,14 \\
(27,00-61,50)\end{array}$ & $\begin{array}{l}43,51 \pm 9,65 \\
(22,00-60,25)\end{array}$ \\
\hline $40-49$ & 23 & $\begin{array}{l}49,49 \pm 10,16 \\
(34,00-76,75)\end{array}$ & $\begin{array}{l}47,93 \pm 8,91 \\
(38,50-74,50)\end{array}$ & $\begin{array}{l}49,63 \pm 8,90 \\
(36,00-74,50)\end{array}$ & $\begin{array}{l}48,09 \pm 9,11 \\
(36,75-75,75)\end{array}$ & $\begin{array}{l}49,86 \pm 9,60 \\
(37,00-71,00)\end{array}$ & $\begin{array}{l}48,07 \pm 9,45 \\
(35,00-71,00)\end{array}$ & $\begin{array}{l}48,57 \pm 9,12 \\
(35,75-66,75)\end{array}$ & $\begin{array}{l}47,63 \pm 9,40 \\
(34,50-69,75)\end{array}$ \\
\hline $50 \leq$ & 6 & $\begin{array}{l}49,83 \pm 8,85 \\
(40,00-63,50)\end{array}$ & $\begin{array}{l}49,21 \pm 9,96 \\
(31,50-59,00)\end{array}$ & $\begin{array}{l}49,00 \pm 10,97 \\
(34,50-64,25)\end{array}$ & $\begin{array}{l}48,17 \pm 10,71 \\
(30,75-59,50)\end{array}$ & $\begin{array}{l}47,46 \pm 6,16 \\
(40,00-58,00)\end{array}$ & $\begin{array}{l}49,50 \pm 8,63 \\
(34,00-59,25)\end{array}$ & $\begin{array}{l}47,46 \pm 7,48 \\
(38,00-59,50)\end{array}$ & $\begin{array}{l}46,96 \pm 9,68 \\
(31,25-57,00)\end{array}$ \\
\hline Tümü & 56 & $\begin{array}{l}48,53 \pm 9,12 \\
(24,50-76,75)\end{array}$ & $\begin{array}{l}46,52 \pm 9,13 \\
(23,50-74,50)\end{array}$ & $\begin{array}{l}48,48 \pm 8,56 \\
(27,50-74,50)\end{array}$ & $\begin{array}{l}46,02 \pm 8,98 \\
(23,00-75,75)\end{array}$ & $\begin{array}{l}48,75 \pm 8,72 \\
(29,00-71,00)\end{array}$ & $\begin{array}{l}47,53 \pm 8,66 \\
(23,50-71,00)\end{array}$ & $\begin{array}{l}47,67 \pm 8,19 \\
(27,00-66,75)\end{array}$ & $\begin{array}{l}45,86 \pm 9,17 \\
(22,00-69,75)\end{array}$ \\
\hline
\end{tabular}

$*_{n}=$ Örneklem saylsl; BA: Ayakta desteksiz baskın el kavrama kuvveti; BOA: Ayakta desteksiz baskın olmayan el kavrama kuvveti; BAD: Ayakta destekli baskın el kavrama kuvveti; BOAD: Ayakta destekli baskın olmayan el kavrama kuvveti; 
BO: Otururken desteksiz baskın el kavrama kuvveti; BOO: Otururken desteksiz baskın olmayan el kavrama kuvveti; BOD: Otururken destekli baskın el kavrama kuvveti; BOOD: Otururken destekli baskın olmayan el kavrama kuvveti

Tablo 8. Kastamonu ve Bursa yöresindeki toplam yangın işçilerinin yaşa göre sekiz test pozisyonundaki kavrama kuvveti değerleri (kg-f)

\begin{tabular}{|c|c|c|c|c|c|c|c|c|c|}
\hline $\begin{array}{l}\text { Yaş } \\
\text { Aralığ }\end{array}$ & $n^{*}$ & $\mathrm{BA}^{*}$ & BOA* & BAD* & BOAD* & BO* & BOO* & BOD* & BOOD* \\
\hline $18-29$ & 30 & $\begin{array}{l}49,01 \pm 7,66 \\
(32,50-66,00)\end{array}$ & $\begin{array}{l}47,85 \pm 8,64 \\
(32,75-64,50)\end{array}$ & \begin{tabular}{|l|}
$50,69 \pm 8,28$ \\
$(35,00-71,25)$
\end{tabular} & $\begin{array}{l}49,28 \pm 8,88 \\
(33,50-69,00)\end{array}$ & $\begin{array}{l}49,43 \pm 7,99 \\
(33,75-67,50)\end{array}$ & $\begin{array}{l}49,88 \pm 8,09 \\
(31,50-65,00)\end{array}$ & $\begin{array}{l}50,73 \pm 7,87 \\
(36,00-65,75)\end{array}$ & $\begin{array}{l}50,49 \pm 8,33 \\
(34,00-68,25)\end{array}$ \\
\hline 30-39 & 42 & $\begin{array}{l}48,48 \pm 7,61 \\
(24,50-62,00)\end{array}$ & $\begin{array}{l}47,93 \pm 8,22 \\
(23,50-64,50)\end{array}$ & \begin{tabular}{|l|}
$49,52 \pm 7,57$ \\
$(27,50-64,50)$
\end{tabular} & \begin{tabular}{|l|}
$48,47 \pm 8,38$ \\
$(23,00-65,00)$
\end{tabular} & \begin{tabular}{|l}
$49,54 \pm 7,64$ \\
$(29,00-65,00)$
\end{tabular} & \begin{tabular}{|l}
$48,74 \pm 7,19$ \\
$(23,50-62,00)$
\end{tabular} & $\begin{array}{l}49,53 \pm 7,39 \\
(27,00-63,75)\end{array}$ & $\begin{array}{l}47,79 \pm 8,70 \\
(22,00-62,50)\end{array}$ \\
\hline $40-49$ & 66 & $\begin{array}{l}48,03 \pm 9,25 \\
(33,00-76,75)\end{array}$ & $\begin{array}{l}48,03 \pm 8,85 \\
(30,25-74,50)\end{array}$ & \begin{tabular}{|l|}
$49,42 \pm 8,68$ \\
$(33,50-76,00)$
\end{tabular} & $\begin{array}{l}49,31 \pm 8,87 \\
(33,25-75,75)\end{array}$ & $\begin{array}{l}49,09 \pm 8,66 \\
(30,75-72,50)\end{array}$ & $\begin{array}{l}48,35 \pm 8,83 \\
(31,50-71,00)\end{array}$ & $\begin{array}{l}49,54 \pm 9,03 \\
(33,50-77,00)\end{array}$ & $\begin{array}{l}49,01 \pm 9,15 \\
(33,25-73,00)\end{array}$ \\
\hline $50 \leq$ & 20 & $\begin{array}{l}46,16 \pm 8,59 \\
(24,00-63,50)\end{array}$ & $\begin{array}{l}45,33 \pm 9,41 \\
(21,75-59,00)\end{array}$ & \begin{tabular}{|l|}
$47,28 \pm 9,27$ \\
$(23,25-64,25)$
\end{tabular} & $\begin{array}{l}46,00 \pm 9,85 \\
(21,25-59+, 50)\end{array}$ & $\begin{array}{l}46,85 \pm 8,02 \\
(23,00-58,00)\end{array}$ & $\begin{array}{l}45,54 \pm 8,93 \\
(21,25-59,25)\end{array}$ & $\begin{array}{l}47,38 \pm 8,38 \\
(23,75-59,50)\end{array}$ & $\begin{array}{l}45,78 \pm 8,88 \\
(22,25-47,25)\end{array}$ \\
\hline Tümü & 158 & $\begin{array}{l}48,10 \pm 8,46 \\
(24,00-76,75)\end{array}$ & $\begin{array}{l}47,63 \pm 8,68 \\
(21,75-74,50)\end{array}$ & \begin{tabular}{|l|}
$49,42 \pm 8,37$ \\
$(23,25-76,00)$
\end{tabular} & $\begin{array}{l}48,66 \pm 8,85 \\
(21,25-75,75)\end{array}$ & $\begin{array}{l}48,99 \pm 8,16 \\
(23,00-72,50)\end{array}$ & $\begin{array}{l}48,39 \pm 8,31 \\
(21,25-71,00)\end{array}$ & $\begin{array}{l}49,49 \pm 8,30 \\
(23,75-77,00)\end{array}$ & $\begin{array}{l}48,56 \pm 8,87 \\
(22,00-73,00)\end{array}$ \\
\hline
\end{tabular}

$*_{n}=$ Örneklem saylsi; BA: Ayakta desteksiz baskın el kavrama kuvveti; BOA: Ayakta desteksiz baskin olmayan el kavrama kuvveti; BAD: Ayakta destekli baskın el kavrama kuvveti; BOAD: Ayakta destekli baskın olmayan el kavrama kuvveti; BO: Otururken desteksiz baskın el kavrama kuvveti; BOO: Otururken desteksiz baskın olmayan el kavrama kuvveti; BOD: Otururken destekli baskın el kavrama kuvveti; BOOD: Otururken destekli baskın olmayan el kavrama kuvveti

Bursa yöresi için yaş grupları arasındaki izometrik kas kuvvetinin farkı varyans analizi ile kontrol edildiğinde yaş grupları arasında istatistiksel olarak fark görülmemiştir ( $p>0,05)$.

Her iki yöre birlikte değerlendirildiğinde de yaş grupları arasındaki izometrik kas kuvvetleri arasındaki fark varyans analizi ile kontrol edildiğinde yaş grupları arasında istatistiksel olarak anlamlı fark görülmemiştir $(\mathrm{p}>0,05)$.

Orman yangın işçilerinin yangın esnasında kullandıkları ana elemanlar arazöze ait su hortumu ve tabancasıdır. $\mathrm{Bu}$ elemanların çaplarının orman yangın işçilerine ait elin uzunluğuna ait antropometrik değerleri (Tablo 2) ile kıyaslandığında hortum çevresi değerinden küçük olduğu ve istatistiksel olarak bu farkl1lığın anlamlı olduğu görülmüştür $(\mathrm{P}<0,05)$. Acar ve Eker (2001) ve Enez ve ark (2008) yaptıkların çalışmalarda orman fidanlık, depo ve üretim işçilerinin kullandıkları aletler ve antropometrik değerleri arasındaki ergonomik uyum değerlendirildiğinde benzer şekilde uyumsuzluklar tespit edilmiştir.

Ekşioğlu ve ark., (2008) Türk İnsanının İzometrik Kavrama Kuvveti Dağılımı üzerine yaptıkları çalışmalarında sadece erkeklere ait verilere bakıldığında tüm değerlerin orman yangın işçilerine ait değerlerden küçük olduğu ve bu durumun istatistiksel olarak anlamlı olduğu görülmüştür $(\mathrm{P}<0,05)$. Ancak Ekşioğlu ve ark., (2008) yaptıkları çalışmada ağır işçilere ait verilere bakıldığında ise sadece Ayakta desteksiz baskın olmayan el kavrama kuvveti $\quad(46,1 \pm 4,9<47,63 \pm 8,68) \quad(\mathrm{P}<0,05)$, Otururken desteksiz baskın el kavrama kuvveti $(46,6 \pm 4,8<48,99 \pm 8,16) \quad(\mathrm{P}<0,05)$, Otururken desteksiz baskın olmayan el kavrama kuvveti $(45,4 \pm 5,2<48,39 \pm 8,31) \quad(\mathrm{P}<0,05) \quad$ değerlerinin orman yangın işçilerinden istatistiksel olarak farklı olduğu bulunmuştur. Orman yangın işçilerine ait sıralanan her üç değerin Türk insanına ait ağır işçi katılımcı değerlerinden anlamlı derecede yüksek olduğu görülmüştür. $\mathrm{Bu}$ durum bu çalışma için çalışma yörelerindeki yangın işçilerinin işlerinin ağır ve zor olmasından kaynaklanabileceği gibi çoğunluğunun tarım işçiliği yapmasından (Tablo 3) ve denek sayılarının ve yaşlarının eşit olmamasından da kaynaklanabilir.

Ülkemizdeki orman yangın işçilerinin el kavrama kuvveti ortalama değeri Türk insanının ve literatürde geçen diğer bazı devlet insanlarının el kavrama kuvvetinden daha yüksek bulunmuştur (Tablo 9). $\mathrm{Bu}$ durum beklenmekle birlikte $\mathrm{ABD}(\mathrm{P}=0,137)$ ve İngiliz 
$(\mathrm{P}=0,356)$ toplumuna ait otururken destekli baskın el kavrama kuvvetinin orman yangın işçileri arasındaki fark istatistiksel olarak anlamlı çıkmamıştır $(\mathrm{P}>0,05)$.

Tablo 9. Orman Yangın işçileri ile Türkiye ve Dünyadaki diğer iş grubu işçilerine ait el kavrama kuvveti örnek değerleri

\begin{tabular}{llcc}
\hline & \multicolumn{1}{c}{ Ülke } & BOD* & BOOD* \\
\hline Orman yangın işçileri & Türkiye & $49,49 \pm 8,30$ & $48,56 \pm 8,87$ \\
\hline Ekşioğlu ve ark. (2008) & Türkiye & $45,43 \pm 8,5$ & $44,2 \pm 8,3$ \\
\hline Mathiowetz ve ark. (1985) & ABD & $47,4 \pm 12,8$ & $42,2 \pm 12,5$ \\
\hline Haidar ve ark. (2004) & İngiltere & $49 \pm 9,9$ & $46 \pm 11,4$ \\
\hline Xiao ve ark. (2005) & Çin & $43,9 \pm 7,1$ & $42,1 \pm 7,2$ \\
\hline
\end{tabular}

*BOD: Otururken destekli baskin el kavrama kuvveti; BOOD: Otururken destekli baskin olmayan el kavrama kuvveti

\section{Sonuç ve Öneriler}

Kastamonu ve Bursa yörelerini kapsayan bu çalışmada orman yangın işçilerinin el kavrama kuvvetleri, el uzunlukları, boyları, kiloları ve sosyo-demografik durumları ile bazı sağlık durumları belirlenmiştir. Her bir yangın işçisine sayısal olarak bir rakam verilmiş ve o işçiye ait olan sosyo-demografik özellikler kayıt altına alınmış, el kavrama kuvveti verileri her bir el için sağ ve sol el olmak üzere; Ayakta ve dinamometre desteksiz, Ayakta ve dinamometre destekli, Nötral pozisyonda oturarak ve dinamometre desteksiz, Nötral pozisyonda oturarak ve dinamometre destekli olmak üzere 4 farklı pozisyonda ikişer defa ölçülerek kayıt altına alınmış ve bu şekilde 158 orman yangın işçine ait el kavrama kuvvetleri belirlenmiştir. Beraberinde orman yangın işçilerinin kullandığ 1 arazözlere ait hortum ve tabanca çapları ölçülmek sureti ile çevreleri hesaplanmış ve kullanıcılarının el uzunlukları ile uyumu araştırılmıştır. Buna orman yangınlarındaki arazözlere ait hortum ve tabancaların tutma yerlerinin çevresinin daha küçük yapılmasının uygun olacağ 1 görülmüştür.

Dünyada Amerikan, Çin ve Türk toplumlarının izometrik el kavrama kuvvetleri belirlenmiştir. Fakat toplumun içindeki bireylerin (katılımcıların) meslek gruplarına göre dağılımı çok çeşitlidir. Daha önce ağır el işçileri için yapıldıysa da orman yangın işçileri için böyle bir çalışmaya rastlanmamıştır. Yapmış olduğumuz bu çalışmada Kastamonu ve Bursa yöresindeki yangın işçilerinin el kavrama kuvveti verilerinin Türk toplumunun el kavrama kuvveti verilerinden yüksek olduğunu tespit edilmiştir. Bununla birlikte orman yangın işçilerinin el kavrama kuvveti ile ağır el işi yapan meslek gruplarını kıyasladığımızda baskın ellerde aynı izotermik kol kas gücüne sahip olduğu görülmüştür.

Ekşioğlu ve ark (2008) çalışmasından yola çıkılarak, bu çalışma referans alınarak orman yangın işçilerinin kullandıkları el aletleri ile kol kas kuvvetleri ve ellerine ait antropometrik değerlerin uyumu ortaya konulabilir. Böylece Türk insanına daha uygun ekipmanlarla çalışması ve dinamik kas yorgunluğunun daha aza indirgenmesi sağlanabilir.

Maksimum izometrik kavrama kuvvetinin yanında yangın esnasında kullanılan hortum çaplarının da anlamlı bir şekilde orman yangın işçilerinin el uzunluklarından fazla çıkması bu ekipmanların tasarımında kullanıcılarının fiziksel özelliklerinin de dikkate alınması sağlanmadır.

Not: $\mathrm{Bu}$ çalışmanın bir kısmı 19. Ulusal Ergonomi Kongresinde (27-29 Eylül 2013) sunulmuştur.

\section{Kaynaklar}

Acar, H.H., Eker, M., 2001. Orman Fidanlık ve Depo İşçilerinde Ergonomik Açıdan Antropometrik Özelliklerin Araştırılması, Dokuz Eylül Üniversitesi, 8. Ergonomi Kongresi, 25-26 Ekim 2001, Bildiriler Kitab1 s.229-238, İzmir.

Arıcak B., Küçük Ö., Enez K. 2014. Determination of pumper truck intervention ratios in zones with high fire potential by using 
geographical information system. Journal of Applied Remote Sensing, 8(1), 083598-083598.

Bechtol C.O., Oakland M.D., 1954. Grip Test : The Use of a Dynamometer with Adjustable Handle Spacings. The Journal of Bone and Hand Surgey, 36A(4):820-824.

Büyüköztürk Ş. 2010. Sosyal Bilimler İçin Veri Analizi El Kitab1, ISBN 978-975-6802- 74-8, Pegem Akademi, 201s., Ankara.

Ekşioğlu M., 2004. Relative optimum grip span as a function of hand anthropometry, International Journal of Industrial Ergonomics, Vol 34, pp.112.

Ekşioğlu M. 2004. Relative optimum grip span as a function of hand anthropometry. International Journal of Industrial Ergonomics, 34(1), 1-12.

Ekşioğlu M., Silahlı B., 2008. Türk İnsanının İzometrik Kavrama Kuvveti Dağılımı, 14. Ulusal Ergonomi Kongresi, 30 Ekim-1 Kasım, s.156-163, Trabzon

Enez, K., Aricak, B., Özer, Ç., 2013, Kastamonu Orman Bölge Müdürlüğü Orman Yangın İşçilerinin İzometrik Kavrama Kuvvetinin Belirlenmesi, 27-28-29 Eylül 2013, Balıkesir Üniversitesi 19. Ulusal Ergonomi Kongresi, Balıkesir

Enez, K., Acar, H., H., Arıcak, B., 2009. An Investigation on Harmony of Logging Workers and Their Hand Tools, XIII World Forestry Congress, Buenos Aires, Argentina, 18 - 23 October 2009 (in CD).

Mital A., Kumar S. 1998. Human Muscle Strength Definitions, Measurement and Usage: Part I- Guidelines for the Practitioner. Internetiaonal Journal of Industrial Ergonomics. 22:101-102.

Özdamar K., 2003, SPSS ile biyoistatistik, ISBN 975-6787-07.4, Kaan Kitapevi, 506s. Eskişehir.

URL1.http://web.ogm.gov.tr/birimler/bolgemud urlukleri/istanbul/dokumanlar/belgeler/yer.htm (11.02.2011,14:48).

URL2.http://web.ogm.gov.tr/diger/yanginharek et/sayfalar/mudahaleekip.aspx (09.02.2011,16:36). 